\title{
The influence of intra-arterial infusion of arginine vasopressin on cochlear blood flow in the rat
}

\author{
G.M. McLaren ', J.K.M. Coleman ${ }^{1}$, W.S. Quirk ${ }^{2}$, H.A. Dengerink ${ }^{1}$ and J.W. Wright ${ }^{1}$ \\ ${ }^{1}$ Department of Psychology, Washington State Unicersity, Pullman, Washington, U.S.A. and ${ }^{2}$ Kresge Hearing Research Institute, The Unicersity of \\ Michigan, Ann Arbor, Michigan, U.S.A.
}

(Received 20 August 1990; accepted 13 February 1991)

\begin{abstract}
Intra-arterially infused arginine vasopressin (AVP) elevated systemic blood pressure (BP) in the Sprague-Dawley rat according to a dose-response pattern while cochlear blood flow (CoBF), as measured by laser Doppler flowmetry, was elevated only at the highest dose. Skin blood flow (SBF) decreased significantly with AVP infusion. The local infusion of AVP into the anterior inferior cerebellar artery (AICA), which supplies the common cochlear artery, produced significant dose-dependent reductions in CoBF with no changes in systemic blood pressure. Pretreatment of the local cochlear supplying vessels with an AVP-specific $V_{1}$ receptor antagonist attenuated subsequent AVP-induced decreases in $\mathrm{CoBF}$, thereby demonstrating specificity of the response. These results suggest that $\mathrm{CoBF}$ is reasonably stable in response to systemic AVP infusion until blood pressure exceeds an elevation from base level of approximately $+60 \mathrm{~mm} \mathrm{Hg}$. One of the mechanisms responsible for this autoregulatory response may be vasoconstriction mediated by the interaction of vasoactive peptides such as AVP and its receptors located in the vasculature of the inner ear or in the more peripheral vessels directly supplying the cochlea.
\end{abstract}

Cochlear blood flow; Cochlea; Blood pressure; Arginine vasopressin; Autoregulation; Laser doppler flowmeter

\section{Introduction}

The cochlea receives approximately $1 / 10,000$ of the total cardiac output (Short et al., 1985) primarily by way of the spiral modiolar artery (SMA). The spiral modiolar artery branches off the common cochlear artery which in turn is supplied by the labyrinthine, anterior inferior cerebellar (AICA), and basilar arteries, respectively (Axelsson and Vertes, 1978; Dengerink et al., 1987). Although much effort has been devoted to understanding the vascular anatomy of the cochlea (reviewed by Axelsson and Ryan, 1988; Ryan, 1988; Ryan et al. 1988), far less is known about the mechanisms that may control cochlear blood flow (CoBF). For instance, there is a paucity of information concerning neuropeptide-activated vascular receptor populations in the cochlear vasculature which is the major focus of this investigation.

Although sufficient increases in systemic blood pressure (BP) elevate CoBF (Goodwin et al., 1984; Miller et al., 1983, 1984; Snow and Suga, 1971; Wright et al., 1985), it is clear that autoregulation of CoBF occurs under certain experimental conditions. For example, initial elevations in CoBF produced by intra-arterial infusions of angiotensin II (AII), epinephrine, or

Correspondence to: John W. Wright, Department of Psychology, Washington State University, Pullman, WA 99164-4820, U.S.A. Fax: (509) 335-3421. phenylephrine, diminish and return toward base level despite sustained elevations in BP (Dengerink et al., 1986; Miller et al., 1986; Quirk et al., 1988). These observations appear to fit the classic definition of blood flow autoregulation, viz., the ability of a tissue to maintain a constant blood flow in the presence of an altered perfusion pressure (Bayliss, 1902; Johnson, 1986 for review). This autoregulatory pattern of CoBF during sustained elevations in systemic BP, suggests an active mechanism for moderating blood flow within the cochlea, and/or its supplying vessels.

Recent work in our laboratory has revealed significant $\left[{ }^{125} \mathrm{I}\right] \mathrm{Sar}^{1}$, Ile ${ }^{8}$-AII receptor binding in the cochlear vasculature of young Sprague-Dawley (SD, Coleman, et al., submitted), Wistar-Kyoto (WKY), and spontaneously hypertensive rats (SHR, Cook et al., submitted). Quirk et al. (1989) have reported dose-dependent decreases in CoBF during infusion of AII into the AICA, thus suggesting a potential physiological response mediated by this receptor population. Given that systemic and central infusions of AII have been reported to stimulate the release of the potent vasoconstrictor, arginine vasopressin (AVP, Bonjour and Malvin, 1976; Keil et al., 1984; Phillips, 1979, 1987; Sladeck et al., 1979), the present study evaluated the ability of AVP to influence CoBF when intra-arterially infused. We predicted that infusion of AVP into the carotid artery would yield increases in systemic blood pressure accompanied by no changes in CoBF (maintained constant flow), and decreases in skin blood flow 
(SBF) in agreement with previous findings using AII (Goodwin et al., 1984; Quirk et al., 1989; Wright et al., 1985). The local infusion of AVP into the AICA was expected to produce dose-related reductions in $\mathrm{CoBF}$ with no significant alterations in systemic blood pressure. Pretreatment of the cochlear vasculature and its supplying vessels with an AVP-specific receptor antagonist via the AICA, was predicted to block the subsequent effects of local AVP infusion upon CoBF, thus establishing the specificity of this response to the AVP contractile system. Finally, it was predicted that femoral artery AVP infusion, following AICA AVP receptor antagonist infusion, would yield significant elevations in both systemic BP and CoBF since the vasoconstrictive effects of AVP would be blocked in the cochlear vasculature.

\section{Method}

\section{Animals and peptides}

Adult male Sprague-Dawley rats, derived from stock originally purchased from Charles River, weighing $340-540 \mathrm{~g}$ (mean $\pm \mathrm{SEM}=430 \pm 2 \mathrm{~g}$ ) were utilized in these experiments. The animals were bred and housed in group cages in an American Association for Accreditation of Laboratory Animal Care (AAALAC)-approved vivarium under a $12: 12 \mathrm{~h}$ light/dark cycle initiated at $0700 \mathrm{~h}$ at $22\left( \pm 1^{\circ} \mathrm{C}\right.$ with Purina rat chow and water available ad libitum. Arginine vasopressin (8103) and the $V_{1}$-specific AVP receptor antagonist, $\mathrm{d}\left(\mathrm{CH}_{2}\right)_{5}$ (Tyr)(Me)-AVP (8109) (Kruzynski et al., 1980) were purchased from Peninsula Laboratories (BeImont, CA).

\section{Surgery and instrumentation}

Each animal of Experiment 1 was anesthetized with Ketamine Hydrochloride (Bristol-Myers, and Co.) accompanied by the muscle relaxant Xylazine (Haver and Co.) at doses of 100 and $2 \mathrm{mg} / \mathrm{kg}$ i.m., respectively. Body temperature was maintained at $38 \pm 1^{\circ} \mathrm{C}$ with a heating pad and monitored with a rectal thermistor (Yellow Springs Co. Model 43TK). The right common carotid artery was prepared with a flow-through catheter (PE-60, Clay Adams) designed to permit simultaneous intra-arterial infusion and recording of systemic blood pressure (Quirk et al., 1989) via a Statham transducer (Model P23AC) and a Grass polygraph (Model 5D). The left bulla was exposed ventrally and opened to reveal the cochlea. The probe $(0.9 \mathrm{~mm}$ o.d.) of the laser Doppler flowmeter (Optokinetics Corp., Advanced Model ALF2100) was positioned on the cochlea via a micromanipulator (Stoelting Co., Model MM33) according to procedures described elsewhere (Goodwin et al., 1984; Wright et al., 1985). Recently, LaRouere et al. (1989) reported good correlation between laser Doppler and intravital microscopy mea-

\section{ANTERIOR}

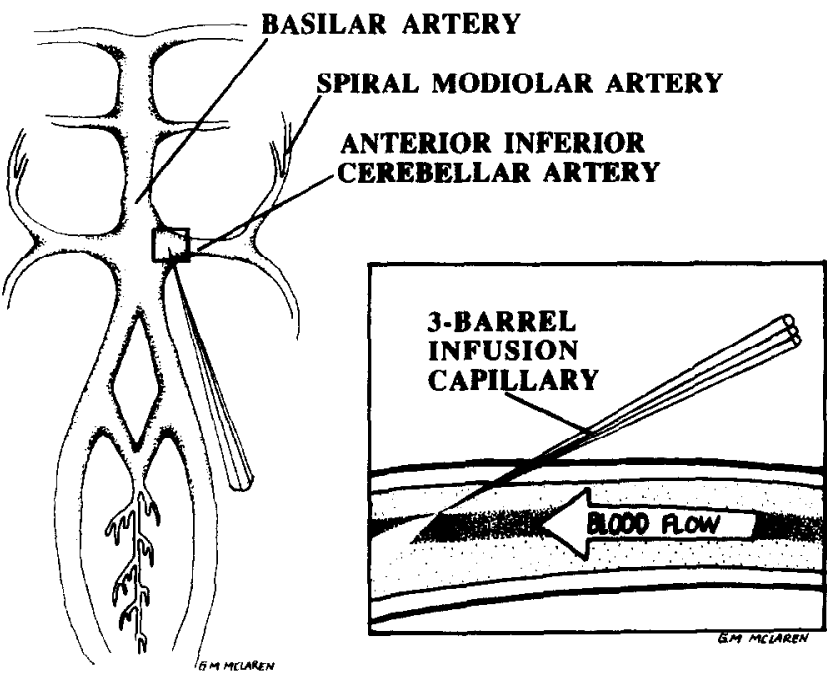

Fig. 1. Inferior view of the exposed vasculature and the position of the 3-barrel glass capillary pipette in the basilar artery such that its infusion outflow entered the anterior inferior cerebellar artery.

sures of regional cochlear blood flow. Additional animals were similarly anesthetized and catheterized, however, hair was removed from the inner right thigh to permit skin blood flow measurement via the laser Doppler flowmeter.

The animals that were used in Experiments 2 and 3 to measure changes in $\mathrm{BP}$ and $\mathrm{CoBF}$ during the infusion of AVP via the AICA were prepared as above. In this case, however, a right femoral artery catheter (PE-50, Clay Adams) was utilized to measure BP and the basilar artery was ventrally exposed to permit infusion into the AICA via a triple-barrel pipette (Fig. 1). Additionally, a tracheostomy was performed on each animal to insure a clear airway. The pipettes used in these experiments had a total outside diameter of 20 $\mu \mathrm{m}$ and each barrel was junctioned with PE-10 tubing attached to a $10 \mu \mathrm{l}$ syringe (Hamilton, Model 701). Each syringe was driven by a microinfusion pump (Razel, Model A99) at a flow rate of $100 \mathrm{nl} / \mathrm{min}$. Each barrel was preloaded with $0.15 \mathrm{M} \mathrm{NaCl}, \mathrm{AVP}$ or the AVP antagonist. In a preliminary investigation $0.5 \%$ Evans blue dye in $0.15 \mathrm{M} \mathrm{NaCl}$ was infused so that the laminar flow could be visualized under a surgical microscope. The position of the pipette tip was adjusted at the junction of the basilar artery and the AICA for optimum delivery of the infusant (Fig. 1).

In Experiment 4, each animal was prepared with separate right and left femoral artery catheters to permit an uninterrupted measurement of systemic blood pressure and a separate infusion route. These animals were then prepared identically with those animals participating in Experiments 2 and 3 . In this experiment only two of the three barrels of each pipette 
were utilized, one barrel was preloaded with $0.15 \mathrm{M}$ $\mathrm{NaCl}$ and the other with an AVP-specific receptor antagonist.

\section{Experiment 1: Effects of intra-arterial infusion of AVP on CoBF and SBF}

Forty-eight rats were randomly assigned to 6 groups (8 cach). Base-level BP and CoBF were established during a $10 \mathrm{~min}$ pre-infusion period. Members of Group 1 served as controls and received two 10-min infusions of $0.15 \mathrm{M} \mathrm{NaCl}(50 \mu \mathrm{l} / \mathrm{min})$ via the flow-through catheter. These infusions were separated by $10 \mathrm{~min}$. Four of the animals of Group 2 received a $10 \mathrm{~min}$ infusion of $0.15 \mathrm{M} \mathrm{NaCl}$ followed $10 \mathrm{~min}$ later by a 10 min infusion of AVP at a dose of $0.1 \mathrm{pmol} / 50 \mu 10.15$ $\mathrm{M} \mathrm{NaCl} / \mathrm{min}$. The other four animals of this group received the AVP infusion first and the $0.15 \mathrm{M} \mathrm{NaCl}$ second (i.e. a counter-balanced design). The animals in Groups 3-5 were treated equivalently to Group 2, however, AVP doses of 1,10 and $100 \mathrm{pmol} / 50 \mu \mathrm{l} 0.15$ $\mathrm{M} \mathrm{NaCl} /$ min were utilized, respectively. An additional group of 24 animals was used to assess the influence of intra-arterially infused AVP on skin blood flow. Subgroups of 8 animals received 10 min infusions of 0.15 $\mathrm{M} \mathrm{NaCl}(50 \mu \mathrm{l} / \mathrm{min})$ via the flow-through catheter, and one dose of AVP $(1,10$ or $100 \mathrm{pmol} / 50 \mu 10.15 \mathrm{M}$ $\mathrm{NaCl} / \mathrm{min}$ ). Within these subgroups, 4 animals received $0.15 \mathrm{M} \mathrm{NaCl}$ first and AVP second, while the other 4 animals received AVP first and $0.15 \mathrm{M} \mathrm{NaCl}$ second. A minimum of $10 \mathrm{~min}$ was permitted between treatments to recover base-level blood pressure and CoBF. Independent groups were used to examine each dose of AVP because of the long lasting pressor effects induced by AVP, particularly at the higher doses.

\section{Experiment 2: Anterior inferior cerebellar artery (AICA) AVP infusion}

Twenty-four animals were assigned to 3 groups ( 8 each) and received two $10 \mathrm{~min}$ AICA infusions (100 $\mathrm{nl} / \mathrm{min}$ ), separated by at least $10 \mathrm{~min}$. Group 1 animals received two infusions of $0.15 \mathrm{M} \mathrm{NaCl}$ and served as control animals. The rats in Group 2 received $10 \mathrm{pmol}$ AVP and $0.15 \mathrm{M} \mathrm{NaCl}$, while the animals in Group 3 received $100 \mathrm{pmol}$ AVP and $0.15 \mathrm{M} \mathrm{NaCl}$ AICA infusions. Four animals in Groups 2 and 3 received the AVP infusion first, while the remaining four animals received the AVP infusion second.

\section{Experiment 3: Local AVP receptor antagonist pretreat- ment}

This experiment employed six animals, three of which received a $10 \mathrm{~min}$ AICA pretreatment infusion of $0.15 \mathrm{M} \mathrm{NaCl}(100 \mathrm{nl} / \mathrm{min})$ followed $10 \mathrm{~min}$ later by a $10 \mathrm{~min}$ infusion of AVP $(100 \mathrm{pmol} / 100 \mathrm{nl} 0.15 \mathrm{M}$ $\mathrm{NaCl} / \mathrm{min})$. Once base-levels were re-established these animals were then pretreated with a $10 \mathrm{~min}$ infusion of the AVP antagonist ( $10 \mathrm{nmol} / 100 \mathrm{nl} 0.15 \mathrm{M} \mathrm{NaCl} / \mathrm{min}$ ) followed $10 \mathrm{~min}$ later by a $10 \mathrm{~min}$ infusion of AVP (100 $\mathrm{pmol} / 100 \mathrm{nl} 0.15 \mathrm{M} \mathrm{NaCl} / \mathrm{min}$ ). The other three animals in this group received the antagonist pretreatment first and then the $0.15 \mathrm{M} \mathrm{NaCl}$ pretreatment second.

\section{Experiment 4: Local AVP-receptor antagonist pretreat- ment followed by AVP femoral artery infusions}

Eight animals were assigned to 2 groups ( 4 each). In each group, baselevel BP and CoBF were established during a $10 \mathrm{~min}$ period prior to each infusion. All animals received two separate infusions of AVP (10 $\mathrm{pmol} / 50 \mu \mathrm{l} 0.15 \mathrm{M} \mathrm{NaCl} / \mathrm{min}$ for $10 \mathrm{~min}$ ) via the femoral artery infusion catheter following a $10 \mathrm{~min}$ infusion of either $0.15 \mathrm{M} \mathrm{NaCl}$ or the AVP antagonist via the AICA. The animals in Group 1 received the AVP-specific antagonist at a dose of $1 \mathrm{nmol} / 100 \mathrm{nl}$ $0.15 \mathrm{M} \mathrm{NaCl} / \mathrm{min}$ while the members of Group 2 received AVP antagonist at a dose of $2 \mathrm{nmol} / 100 \mathrm{nl}$ $0.15 \mathrm{M} \mathrm{NaCl} / \mathrm{min}$. Two animals in Group 1 received the control pretreatment infusion first while the remaining two animals received the antagonist infusion first. All members of Group 2 received the $0.15 \mathrm{M}$ $\mathrm{NaCl}$ pretreatment infusion first.

\section{Statistical analysis}

Systemic blood pressure and $\mathrm{CoBF}$ were scored every $30 \mathrm{~s}$ throughout each pre-infusion, infusion, and post-infusion period in $\mathrm{mm} \mathrm{Hg}$ and percent change from base-level, respectively. Differences in baselevel BP among groups used in Experiments 1-4 were analyzed via one-way analyses of variance (ANOVA). In Experiment 1, changes in BP and CoBF were analyzed by separate 5 (dose) $\times 10$ (time points) repeated measures ANOVAs. BP and SBF data taken from the additional animals of Experiment 1 were analyzed via separate 4 (dose) $\times 10$ (time points) repeated measures ANOVAs. In Experiment 2, alterations in BP and CoBF during AICA infusions were analyzed via separate 3 (dose) $\times 10$ (time points) repeated measures ANOVAs. In Experiment 3, changes in $\mathrm{BP}$ and $\mathrm{CoBF}$ during AICA pre-treatment and AVP infusions were analyzed via separate 1 (group) $\times 4$ (treatments) ANOVAs. Post-hoc comparisons were made via subsequent 1 (group) $\times 2$ (treatments) ANOVAs. Changes in systemic $\mathrm{BP}$ and $\mathrm{CoBF}$ were measured during each pre-infusion and infusion period in Experiment 4. Base-level systemic BP for animals in this experiment were analyzed by a 1-between $\Lambda$ NOVA. Alterations in $\mathrm{BP}$ from baselevel during the $10 \mathrm{pmol}$ femoral artery 
infusions were analyzed via separate 2-within ANOVAs for each pretreatment condition. Differences in BP betwcen groups during AVP infusions were analyzed via 1-between, 2-within ANOVAs. Changes in BP and CoBF during the local AICA pretreatments were analyzed via separate 1-between, 1-within ANOVAs. Comparisons between mean percent changes in CoBF from base-levels during the $10 \mathrm{pmol}$ AVP infusions were made by separate 2-within ANOVAs while comparisons between groups (dose) were made via 1-between, 1-within ANOVAs. Newman-Keuls tests were used to make post-hoc comparisons $(P<0.05)$.

\section{Results}

Experiment 1: Effects of intra-arterial infusion of AVP on $\mathrm{CoBF}$

There were no significant differences in mean anesthetized baselevel BP among the 6 groups in this experiment. An overall mean ( \pm SEM) baselevel anesthetized BP of $102( \pm 2) \mathrm{mm} \mathrm{Hg}$ was observed for these animals. Fig. 2 presents the effects of intra-arterial infusion of increasing doses of arginine vasopressin on systemic blood pressure. Increases in BP were observed during the initial minutes of the AVP infusion periods and remained elevated for the duration of the infusion. Elevations in BP followed a significant doseresponse pattern $(\mathrm{F}=16.32, \mathrm{df}=36,315, P<0.0001)$ with the higher doses of AVP yielding greater increases. The specific maximum mean $( \pm$ SEM) BP increases observed during the infusions of $0,0.1,1,10$, and 100 pmol AVP were: $0.6( \pm 0.3), 2.5( \pm 0.3)$, $9.3( \pm 0.7), 52.2( \pm 6.3)$, and $83.6( \pm 4.4) \mathrm{mm} \mathrm{Hg}$, respectively. Post-hoc analyses indicated that those animals that received the 1,10 , and $100 \mathrm{pmol}$ doses displayed

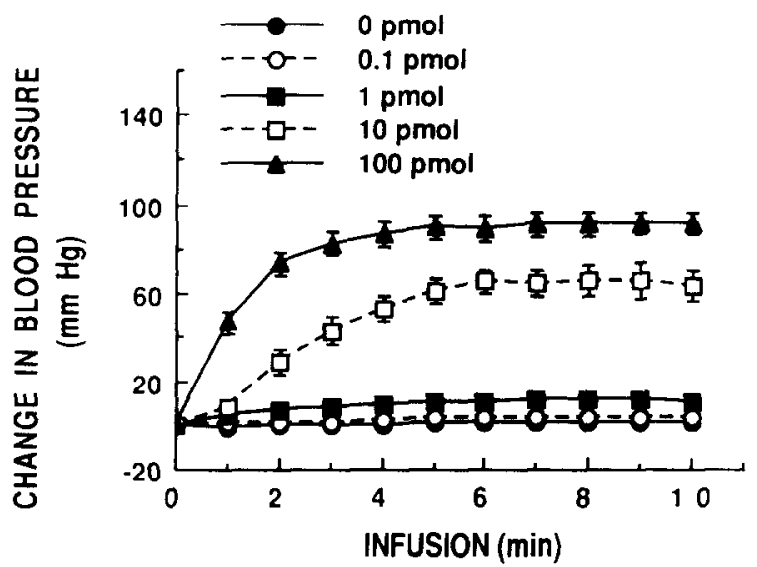

Fig. 2. Mean ( \pm SEM) changes in systemic blood pressure $(\mathrm{mm} \mathrm{Hg})$ from base-level during the $10 \mathrm{~min}$ carotid artery infusions of $0,0.1,1$, 10 , and $100 \mathrm{pmol} A V P / 50 \mu 10.15 \mathrm{M} \mathrm{NaCl} / \mathrm{min}$ in the rat. Base-level mean $( \pm$ SEM) anesthetized blood pressure was $100 \pm 2 \mathrm{~mm} \mathrm{Hg}$.

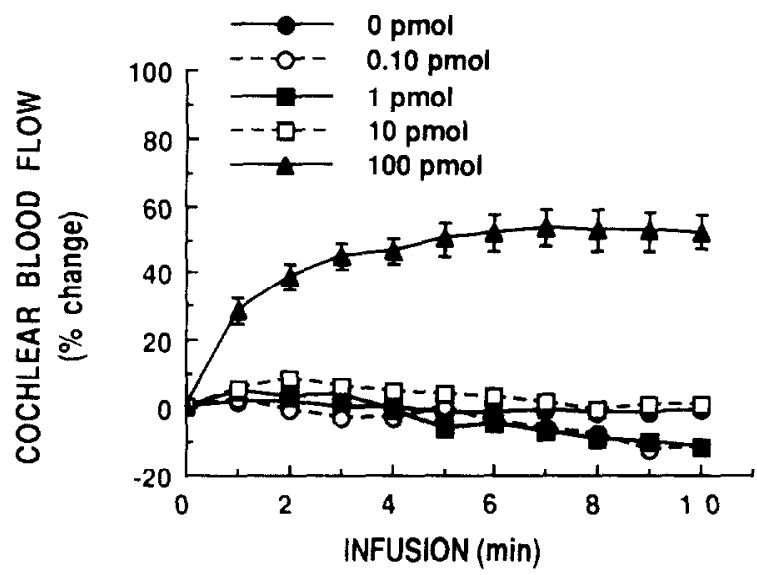

Fig. 3. Mean $( \pm S E M)$ percent changes in $\mathrm{CoBF}$ from base-level during the $10 \mathrm{~min}$ carotid artery infusions of $0,0.1,1,10$, and 100 $\mathrm{pmol} \mathrm{AVP} / 50 \mu 10.15 \mathrm{M} \mathrm{NaCl} / \mathrm{min}$ in the rat.

significant BP elevations as compared with the control group, while the 10 and $100 \mathrm{pmol}$ doses differed from each other and from the other three groups.

Fig. 3 illustrates the influence of increasing doses of intra-arterially infused AVP on CoBF. Although CoBF increased significantly during the infusion of the 100 pmol dose of AVP $(\mathrm{F}=3.04, \mathrm{df}=36,315, P<0.0001)$, no significant alterations in $\mathrm{CoBF}$ were observed during the infusion of any other dose of AVP. Respective mean $( \pm$ SEM $)$ percent changes in CoBF for those groups that received the $0,0.1,1,10$, and $100 \mathrm{pmol}$ doses were: $-0.3( \pm 0.4),-4.5( \pm 1.5),-2.9( \pm 1.8)$, $3.6( \pm 0.9)$, and $47.4( \pm 2.4) \%$.

Fig. 4 presents the mean $( \pm$ SEM) SBF responses during the infusion of $0,1,10$, and $100 \mathrm{pmol}$ AVP. These mean $( \pm$ SEM) SBF responses were significantly different $(\mathrm{F}=31.84$, $\mathrm{df}=3,28, P<0.0001)$. No alterations in SBF were measured during the $0.15 \mathrm{M} \mathrm{NaCl}$ infusions, however AVP infusions (1, 10, and $100 \mathrm{pmol})$ resulted in sustained decreases in SBF significantly

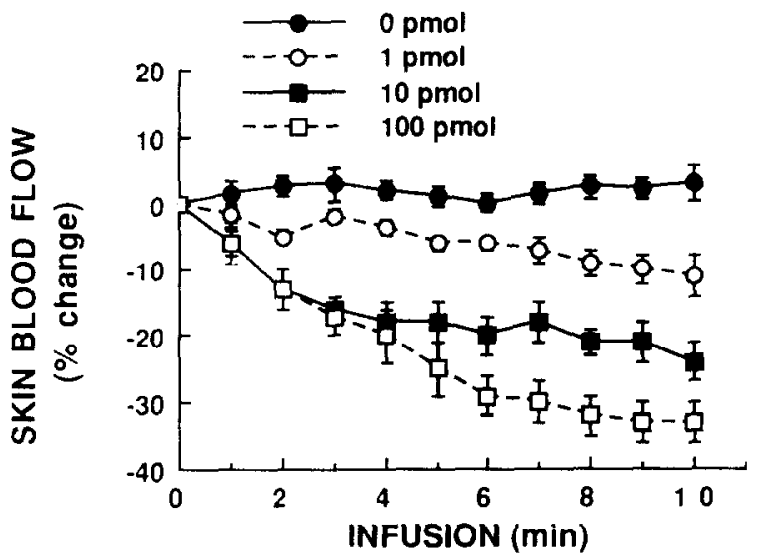

Fig. 4. Mean ( \pm SEM) percent changes in SBF from base-level during the 10 min carotid artery infusions of $0,1,10$, and $100 \mathrm{pmol}$ $\mathrm{AVP} / 50 \mu \mathrm{l} 0.15 \mathrm{M} \mathrm{NaCl} / \mathrm{min}$. 


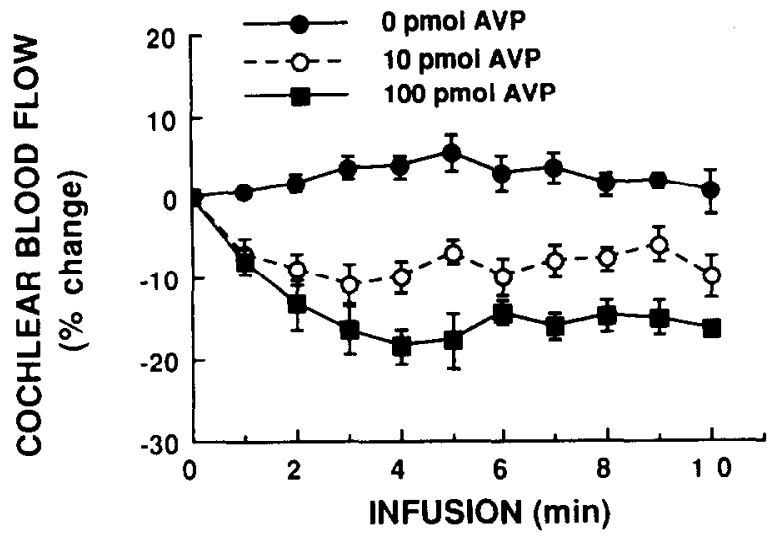

Fig. 5. Mean ( $\pm \mathrm{SEM})$ percent changes in CoBF from base-level during the AICA infusions of 0,10 and $100 \mathrm{pmol} A V P / 100 \mathrm{nl} 0.15$ $\mathrm{M} \mathrm{NaCl} / \mathrm{min}$.

different from $0.15 \mathrm{M} \mathrm{NaCl}(\mathrm{Fs}=21.18,45.3$, and 73.3 respectively, $\mathrm{df}=1,14, P<0.0001$ ). Additionally, posthoc analyses indicated that each dose of AVP produced SBF responses significantly different from the next.

The alterations in SBF were accompanied by significant alterations in BP $(\mathrm{mm} \mathrm{Hg})$ very similar to those reported in Fig. 2. The mean $( \pm$ SEM) pressor responses to $0,1,10$, and $100 \mathrm{pmol}$ AVP were $1( \pm 0.1)$, $9.8( \pm 0.4), 52.5( \pm 5.6)$, and $74.8( \pm 6.0) \mathrm{mm} \mathrm{Hg}$, respectively $(\mathrm{F}=100.6, \mathrm{df}=3,28, P<0.0001)$. Post-hoc analyses revealed that each dose of AVP induced pressor responses different from $0.15 \mathrm{M} \mathrm{NaCl}$ infusion and from each other.

Experiment 2: Anterior inferior cerebellar artery (AICA) AVP infusion

A mean $( \pm$ SEM) anesthetized base-level BP of $103( \pm 1.6) \mathrm{mm} \mathrm{Hg}$ was observed in the three groups of animals used in this experiment. Local AICA infusions of 0,10 , and 100 pmol AVP produced no significant alterations in systemic BP, however, Fig. 5 illustrates the mean $( \pm S E M)$ percent changes in CoBF during AICA infusion of AVP. Dose-dependent decreases in CoBF were observed during the infusions of 10 and 100 pmol doses of AVP with the highest AVP dose producing the largest reduction in CoBF. The mean $( \pm$ SEM) percent changes in CoBF observed during the infusion of 0,10 , and 100 pmol AVP were $2.6( \pm 0.5)$, $-8.5( \pm 0.5)$, and $-15.0( \pm 0.9) \%$, respectively, which were statistically different $(\mathrm{F}=40.79, \mathrm{df}=2,21, P<$ 0.0001 ). Post-hoc comparisons indicated that the mean ( \pm SEM) percent changes in CoBF of $0.5( \pm 2.6)$, $-9.5( \pm 2.5)$, and $-16.3(\perp 0.8) \%$ obscrved during the last minute of the 0,10 , and 100 pmol AVP infusions, respectively, were significantly different from one another.
Experiment 3: Local AVP receptor antagonist pretreatment

A mean $( \pm$ SEM) anesthetized BP of $100.8( \pm 0.2)$ $\mathrm{mm} \mathrm{Hg}$ was observed in the animals used in this experiment. No significant alterations in $\mathrm{BP}$ were measured during the AICA infusions of $0.15 \mathrm{M} \mathrm{NaCl}, 100$ pmol AVP, or the AVP antagonist. Fig. 6 illustrates the mean $( \pm$ SEM $)$ percent change in CoBF during infusion of AVP following pretreatment with $0.15 \mathrm{M}$ $\mathrm{NaCl}$ or the AVP antagonist. The $0.15 \mathrm{M} \mathrm{NaCl}$ pretreatment did not affect the subsequent mean ( \pm SEM) AVP-induced reductions in CoBF of $17.4( \pm 3.4) \%$; however, pretreatment with the receptor antagonist abolished the AVP-induced reductions in CoBF, yielding a mean $( \pm \mathrm{SEM})$ percent change in CoBF of $+1.2( \pm 0.4) \%$. These values were significantly different $(\mathrm{F}=26.30, \mathrm{df}=3,15, P<0.0001)$.

Experiment 4: Local AVP-receptor antagonist pretreatment followed by AVP femoral artery infusions

A mean $( \pm$ SEM $)$ anesthetized systemic BP of 125 $( \pm 1.0) \mathrm{mm} \mathrm{Hg}$ was observed in the animals of Experiment 4. No significant alterations in BP or CoBF were observed during any of the AICA pretreatment infusions. Following the 0,1 , and 2 nmol pretreatment doses of the AVP antagonist, the subsequent $10 \mathrm{pmol}$ dose of AVP via the femoral artery catheter produced significant mean $( \pm$ SEM) increases in BP of $70.1( \pm 5.2), 68.2( \pm 3.3)$, and $74.0( \pm 4.3) \mathrm{mm} \mathrm{Hg}$, respectively ( $\mathrm{Fs}=124.50,347.37$, and 182.55 respectively, $\mathrm{df}=1,3, P<0.001)$.

Figure 7 presents the mean ( \pm SEM) percent change in $\mathrm{CoBF}$ during femoral artery infusion of AVP following the $10 \mathrm{~min} 0,1$, and $2 \mathrm{nmol}$ AVP antagonist AICA pretreatment infusions. It can be seen that CoBF slowly

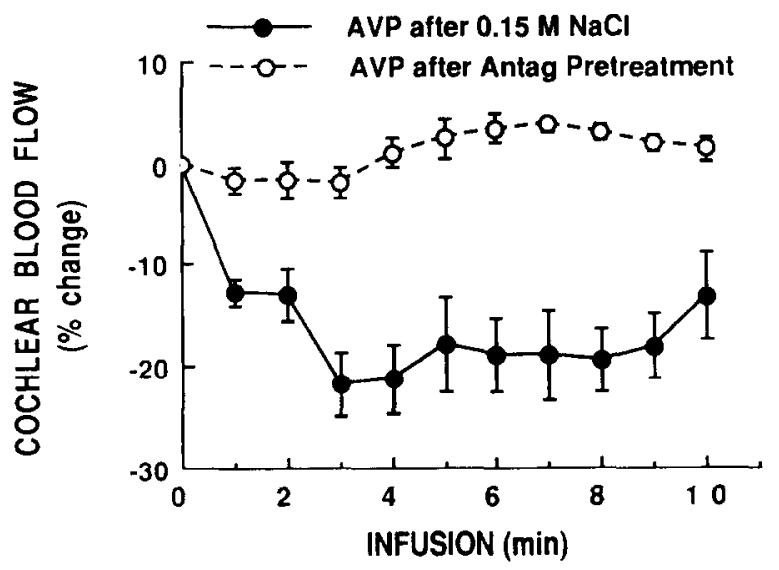

Fig. 6. Mean ( \pm SEM) percent changes in CoBF from base-level during $10 \mathrm{~min}$ AICA infusions of AVP $(100 \mathrm{pmol} / 100 \mathrm{nl} 0.15 \mathrm{M}$ $\mathrm{NaCl} / \mathrm{min}$ ) following a $10 \mathrm{~min}$ pretreatment with either the AVPspecific receptor antagonist or $0.15 \mathrm{M} \mathrm{NaCl}$. 


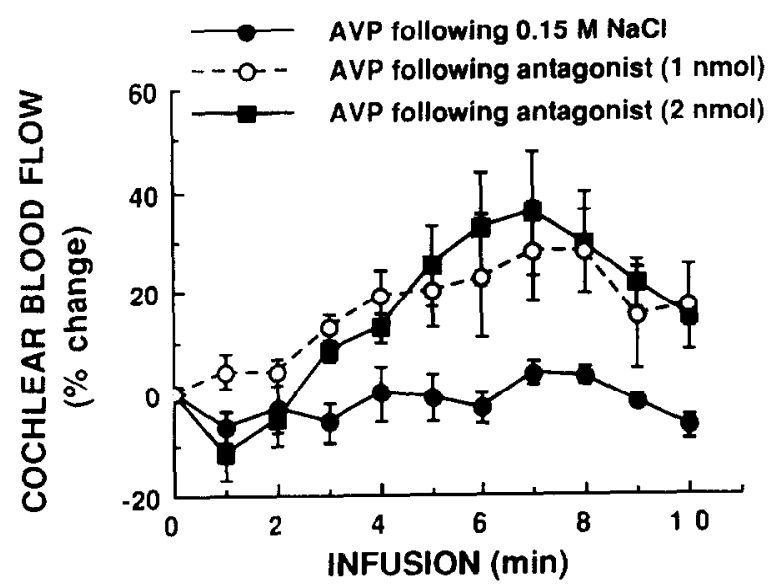

Fig. 7. Mean ( $\pm \mathrm{SEM})$ percent changes in $\mathrm{CoBF}$ during the femoral artery infusions of AVP $(10 \mathrm{pmol} / 50 \mu 10.15 \mathrm{M} \mathrm{NaCl} / \mathrm{min})$ following local AVP antagonist $(0,1$ and $2 \mathrm{nmol} / 100 \mathrm{nl} 0.15 \mathrm{M} \mathrm{NaCl} / \mathrm{min})$ pretreatments.

increased during the AVP femoral artery infusions that had been preceded by the local AVP antagonist pretreatments and then slowly decreased toward baselevel; however, BP remained elevated throughout the AVP femoral artery infusion periods. Significant mean percent increases in $\mathrm{CoBF}$ were observed only during the AVP infusions following pretreatment with the antagonist $(1$ and $2 \mathrm{nmol})$ via local infusion $(F=62.66$, $\mathrm{df}=1,3, P<0.004)$, and $(\mathrm{F}=35.22, \mathrm{df}=1,3, P<$ $0.009)$, respectively. Maximum mean $( \pm$ SEM) percent increases in CoBF were $7.9( \pm 1.9), 32.0( \pm 4.0)$, and $40.0( \pm 5.2) \%$ following the 0,1 , and $2 \mathrm{nmol}$ antagonist pretreatment conditions measured during AVP infusion, respectively. Although slightly higher increases in CoBF were observed following the $2 \mathrm{nmol}$ antagonist pretreatment, these increases were not significantly different from those observed following the $1 \mathrm{nmol}$ antagonist infusion.

An order effect was observed in this experiment. In general, increases in CoBF were greater than expected during control infusions if the antagonist was administered prior to the control condition. Therefore, the antagonist $(2 \mathrm{nmol})$ was administered last to the animals of Group 2.

\section{Discussion}

Autoregulation in cerebral vessels has been confirmed (e.g., Baumbach and Heistad, 1985) and suggested as a model system for investigating CoBF (Lawrence et al., 1977; Miller et al., 1983; Miller and Dengerink, 1988). The hypothesis that CoBF is under local autoregulatory control has been proposed by several authors (Dengerink et al., 1985; Flynn et al., 1988; Hultcrantz et al., 1982: La Rouere et al., 1989; Miller et al., 1983, 1984; Quirk et al., 1988, 1989), and was recently confirmed by Quirk et al. (1989) in the rat. These investigators (Quirk et al., 1989) intra-arterially infused angiotensin II or phenylephrine in order to produce elevations in systemic blood pressure and measured initial elevations in CoBF followed by a slow recovery of base-level CoBF despite sustained elevations in blood pressure. In a companion experiment, AII was infused into the AICA and resulted in significant reductions in CoBF without altering systemic blood pressure. If the AICA was pretreated with an AII receptor antagonist, these AII-induced reductions in CoBF were blocked. These results suggested that angiotensin receptors are present in the cochlear vasculature and could be activated by blood-borne AII resulting in vasoconstriction. As previously indicated, AII receptors have now been identified in the cochlear vasculature of young rats using autoradiographic techniques (Coleman et al., submitted; Cook et al., submitted).

The results from the present investigation confirmed our expectation that exogenous infusion of arginine vasopressin would produce vasoactive effects in the cochlea. The results from local infusion of AVP and an AVP-specific receptor antagonist into the AICA suggest that an AVP receptor population may be present in the vessels directly supplying the cochlea or possibly in those vessels housed within the otic capsule. This receptor population may be capable of mediating a vasocontractile response. Additionally, the results from AICA pretreatment with an AVP antagonist followed by femoral artery AVP infusions suggest that AVP and its vascular receptors may participate in tonic control of CoBF during AVP-induced elevations in systemic blood pressure, however, this tonic control may be overcome by an elevation of $60 \mathrm{~mm} \mathrm{Hg}$ or greater in systemic blood pressure. Presently, there is no available information confirming the presence of AVP receptors in the cochlear microvasculature, however, our laboratory has initiated such an investigation utilizing autoradiographic techniques.

Angiotensin II and AVP are clearly not the only vasoactive ligands present in the cochlear vasculature. The autonomic nervous system innervates the cochlea (Lorente de No, 1937; Smith, 1951) providing adrenergic fibers that make contact with vessels of the inner ear such as the spiral modiolar artery (Spoendlin and Lichtensteiger, 1966) and vessels of the osseous spiral lamina and tympanic lip (Brechtelsbauer et al., 1990). Although innervation has been confirmed by electron microscopy (Densert, 1974; Densert and Flock, 1974; Prazma et al., 1990), little is known about the contribution these fibers may make to regulation of $\mathrm{CoBF}$. The potential role of peptides in CoBF is even less well understood. Matsuyama et al. (1986), using immunohistochemical techniques, reported the presence of substance $\mathrm{P}$, calcitonin gene-related peptide, vasoactive 
intestinal polypeptide, and neuropeptide Y-like fibers in the basilar artery of the guinea pig and rat. More recently, Carlisle et al. (1990) reported the presence of fibers for these same peptides along the length of the guinca pig spiral modiolar artery using immunoflourescent and histofluorescent techniques. These results suggest that there may be vascular receptors for these compounds in the SMA as well.

Several conclusions can be drawn from the results of the present experiments. First, intra-carotid artery infusion of AVP yielded dose-related elevations in systemic blood pressure with increases in CoBF noted only with the highest dose of AVP administered (100 pmol). Significant elevations in systemic blood pressure were observed during the $10 \mathrm{pmol}$ AVP infusion, however, no alterations in CoBF were associated with this pressure increase. Such a pattern of CoBF responses would be expected if CoBF were under local control. Second, the intra-carotid infusion of AVP yielded significant reductions in skin blood flow. These results suggest that blood flow to peripheral tissues such as the skin may be compromised during periods of heightened systemic blood pressure induced by infusion of exogenous AVP. Third, infusion of AVP into the AICA produced dose-related reductions in $\mathrm{CoBF}$ with no alterations in systemic blood pressure. Pretreatment of the cochlear supplying vessels with an AVP-specific receptor antagonist significantly attenuated these reductions thus linking this vasocontractile response to the interaction of AVP with a population of vascular AVP receptors in the cochlea or its supplying vessels. Fourth, intra-arterial infusion of the $10 \mathrm{pmol}$ dose of AVP significantly elevated $\mathrm{BP}$ with no associated alteration in CoBF (Experiment 1); however, if this infusion was preceded by a local AICA infusion of an AVPspecific $V_{1}$ receptor antagonist, significant elevations in both systemic BP and CoBF were measured (Experiment 4). These results suggest that vascular receptors may contribute to tonic control (i.e., autoregulation) of CoBF during elevations in systemic BP, however, this tonic control may be overcome by increases of $60 \mathrm{~mm}$ $\mathrm{Hg}$ or greater in blood pressure which forces an increase in $\mathrm{CoBF}$, or by delivering the ligand directly into the cochlear vasculature which presumably decreases the exposure time to blood peptidase activity, resulting in reductions in $\mathrm{CoBF}$, or by blocking these receptors with an AVP antagonist.

In sum, these results further support the hypothesis that peptide receptors are present in the vasculature of the cochlea and that activation of these receptors by blood-borne peptides (e.g. All and AVP) may play a role in the regulation of CoBF. The present findings, coupled with previous work from our laboratory (Dengerink et al., 1986; Quirk et al., 1988, 1989), support an autoregulatory model of cochlear blood flow which may in part be mediated by the interaction of circulat- ing vasoactive peptides with their vascular receptor populations in the vessels supplying the inner ear. Further, confirmation of this hypothesis must await demonstration that peptide receptor populations, in addition to angiotension II, are in fact present in these cochlear vessels.

\section{Acknowledgements}

This research was supported by funds provided by the Deafness Research Foundation and Washington State University. We wish to thank Dr. Jim Whipple for his comments concerning the statistical procedures and Mrs. Ruth Day for her excellent editorial assistance.

\section{References}

Axelsson, A. and Ryan, A. (1988) Circulation of the inner ear: Comparative study of the vascular anatomy in the mammalian cochlea. In: A.F. Jahn and J. Santos-Sacchi (Eds.), Physiology of the Ear, Raven Press, New York, pp. 295-315.

Axelsson, A. and Vertes, D. (1978) Vascular histology of the guinea pig cochlea. Acta Otolaryngol. (Stockh) 85, 198-212.

Baumbach, G. and Heistad, D. (1985) Regional, segmental and temporal heterogeneity of cerebral vascular autoregulation. Ann. Biomed. Eng. 13, 303-310.

Bayliss, W. (1902) On the local actions of the arterial wall to changes in internal pressure. J. Physiol. (Lond) 28, 220-231.

Bonjour, J. and Malvin, R. (1976) Stimulation of ADH release by the renin-angiotensin system. Am. J. Physiol. 218, 1555-1559.

Brechtelsbauer, P.B., Prazma, J., Garrett, C.G. and Pillsbury, H.C. (1990) Immunocytochemical localization of tyrosine hydroxylase in the gerbil cochlea. Assoc. Res. Otolaryngol. Abstr. 13, 359.

Carlisle, L., Aberdeen, J., Forge, A. and Burnstock, G. (1990) Neural basis for regulation of cochlear blood flow: Peptidergic and adrenergic innervation of the spiral bodiolar artery of the guinea pig. Hear. Res. 43, 107-114.

Coleman, J.K.M., Cook, V.I., Grove, K.E., Wright, J.W., Dengerink, H.A. and Speth, R.C. (1991) Sar ${ }^{1}$, Ile ${ }^{8}$-AII receptor binding in the cochlea of young Sprague-Dawley rat pups. (submitted).

Cook, V.I., Coleman, J.K.M., Grove, K.E., Harding, J.H. and Speth, R.C. (1991) Perinatal comparison of $\mathrm{Sar}^{1}, \mathrm{Ilc}^{8}$-AlI receptor binding in the cochlea of SHR and WKY rats. (submitted).

Dengerink, H.A., Axelsson, A., Wright, J. and Miller, J. (1987) Histological measures of cochlear blood flow: A validation study. Acta Otolaryngol. (Stockh.) 104, 113-118.

Dengerink, H.A., Wright, J.W., Dengerink, J.E., and Miller, J.M. (1986) A pathway for the interaction of stress and noise influences on hearing. In: R. Salvi, D. Henderson, R. Hamernik, and V. Colletti (Eds.), Basic and Applied Aspects of Noise-Induced Hearing Loss, Plenum Press, New York, pp. 559-569.

Dengerink, H.A., Wright, J. Miller and Goodwin, P. (1985) The effects of nicotine on laser Doppler measures of cochlear blood flow. Hear. Res. 20, 31-36.

Densert, O. (1974) Adrenergic innervation in the rabbit cochlea. Acta Otolaryngol. (Stockh) 78, 345-356.

Densert, O. and Flock, A. (1974) An electron microscopic study of adrenergic innervation of the cochlea. Acta Otolaryngol. (Stockh.) $77,185-197$. 
Flynn, A.J., Dengerink, H.A. and Wright, J.W. (1988) Blood pressure in resting, anesthetized and noise-exposed guinea pigs. Hear. Res. 34, 201-206.

Goodwin, P., Miller, J., Dengerink, H., Wright, J. and Axelsson, A (1984) The laser Doppler: A non-invasive measure of cochlear blood flow. Acta Otolaryngol. (Stockh) 98, 403-412.

Hultcrantz, E., Hillerdal, M. and Angelborg, C. (1982) Effect of nicotinic acid on cochlear blood flow. Acta Otorhinolaryngol. $234,151-155$

Johnson, P.C. (1986) Autoregulation of blood flow. Circ. Res. 59. $483-495$

Keil, L.C., Rosella-Dampman, L.M., Emmert, S., Chee, O. and Summy-Long, J.Y. (1984) Enkephalin inhibition of angiotensin stimulated release of oxytocin and vasopressin. Brain Res. 297 329-336.

Kruzynski, M., Lammek, B., Manning, M., Seto, J., Haldar, J. and Sawyer, W. (1980) Highly potent antagonists of the vasopressor response to arginine vasopressin. J. Med. Chem. 23, 364-367.

LaRouere, M.J., Sillman, J.S., Nuttall, A.L. and Miller, J.M. (1989) A comparison of laser Doppler and intravital microscopic measures of cochlear blood flow. Otolaryngol. Head-Neck Surg. 101. 375-384.

Lawrence, M., Nuttall, A.L. and Burgio, P.A. (1977) Oxygen reserve and autoregulation in the cochlea. Acta Otolaryngol. 83, 146-152.

Lorente de No, R. (1937) The sensory endings in the cochlea. Laryngoscope 47, 373-377.

Matsuyama, T., Wanaka, A., Yoneda, S. and Tohyama, M. (1986) Multiple neuronal innervation of the cerebral blood vessels: An immunohistochemical study. In: H. Nakamura (Ed.), Brain and Blood Pressure Control, Elsevier Publishing, pp. 427-436.

Miller, J.M. and Dengerink, H.A. (1988) Control of inner ear blood flow. Am. J. Otolarygol. 9, 302-316.

Miller, J.M., Goodwin, P.C. and Marks, N.J. (1984) Inner ear blood flow measured with a laser Doppler system. Arch Otolaryngol. $110,305-308$

Miller, J.M., Hultcrantz, E., Short, S., and Nuttall, A.L. (1986) Pharmacological effects on cochlear hlood flow measured with the laser Doppler technique. Suppl. Scand. Audiol. (Stockh) 26 , $11-20$.

Miller, J.M., Marks, N.J. and Goodwin, P.C. (1983) Laser Doppler measurements of cochlear blood flow. Hear. Res. 11, 385-394.
Phillips, I.M. (1987) Functions of angiotensin in the central nervous system. Ann. Rev. Physiol. 49, 413-435.

Phillips, I.M., Weyhenmeyer, J., Felix, D., Ganten, D., and Hoffman, E. (1979) Evidence for an endogenous brain renin-angiotensin system. Fed. Proc. 38, 2260-2264.

Prazma, J., Carrasco, V.N., Brechtelsbauer, P.B. and Pillsbury, H.C. (1990) Fluorescent carbocyanine dye "DiI" staining of nerve structures in cochlea. ARO Midwinter Meet., 4-8 February, St. Petersburg, FL.

Quirk, W.S., Wright, J.W., Dengerink, H.A., and Miller, J.M. (1988) Angiotensin II-induced changes in cochlear blood flow and blood pressure in normotensive and spontaneously hypertensive rats. Hear. Res. 32, 129-136.

Quirk, W.S., Dengerink, H.A., Coleman, J.K.M. and Wright, J.W. (1989) Cochlear blood flow autoregulation in Wistar-Kyoto rats. Hear. Res. 41, 53-60.

Ryan, A.F. (1988) Circulation of the inner ear: II. The relationship between metabolism and blood flow in the cochlea. In: A.F. Jahn and J. Santos-Sacchi (Eds.), Physiology of the Ear. Raven Press, New York, 317-325

Ryan, A.F., Axelsson, A., Myers, R. and Woolf, N.H. (1988) Changes in cochlear blood flow during acoustic stimulation as determined by ${ }^{14} \mathrm{C}$-iodoantipyrine autoradiography. Acta Otolaryngol. (Stockh.) 105, 232-241.

Short, S., Goodwin, P.C. and Kaplan J.N. (1985) Measuring cochlear blood flow using laser Doppler spectroscopy. J. Otolaryngol. Head-Neck Surg. 93, 786-793.

Sladeck, C.D. and Joynt, R.J. (1979) Angiotensin stimulation of vasopressin release from the rat hypothalamoneurohypophyseal system in organ culture. Endocrinology 41, 148-153.

Smith, C.A. (1951) Capillary areas of the cochlea in the guinea pig. Laryngoscope 61, 1073-1095.

Snow, J.B. and Suga, F. (1971) Labyrinthine vasodilators. Arch. Otolaryngol. 97, 365-370.

Spoendlin, H. and Lichtensteiger, W. (1966) The adrenergic innervation of the labyrinth. Acta Otolaryngol. (Stockh) 61, 423-434.

Wright, J.W., Dengerink, H.A., Miller, J. and Goodwin, P. (1985) Noise-induced increases in inner ear blood flow: The potential role of angiotensin II. Hear. Res. 17, 41-46. 